\title{
Development and field-testing of the Dementia Carer Assessment of Support Needs Tool (DeCANT)
}

\section{Trine Holt Clemmensen, 1,2 (1) Hanne Kaae Kristensen,, Karen Andersen-Ranberg, 3,4 and Henrik Hein Lauridsen²}

${ }^{1}$ Health Sciences Research Centre, UCL University College, Odense, Denmark

${ }^{2}$ Department of Sports Science and Clinical Biomechanics, University of Southern Denmark, Odense, Denmark

${ }^{3}$ Department of Clinical Research, University of Southern Denmark, Odense, Denmark

${ }^{4}$ Department of Public Health, University of Southern Denmark, Odense, Denmark

Objectives: Caring for a person with dementia is associated with poor mental, physical, and social health, which makes it important to consider how carers are best supported in their caring role to preserve both their and the person with dementia's well-being. At present, a robust instrument to assess carers' support needs does not exist. This study aimed to develop a self-reported questionnaire to assess the support needs of carers of people with dementia. The objectives were to: (1) generate items, (2) pilot test, and (3) field-test the questionnaire.

Design: Development and field-testing of a new questionnaire.

Settings: Primary and secondary health and social care of informal carers and people with dementia in nine municipalities and one dementia clinic in a hospital in Denmark.

Participants: Eight experts, 12 carers, and 7 digital users participated in pilot testing. 301 carers participated in field-testing.

Measurements: Items for inclusion were generated based on interviews and literature review. An iterative process of data collection was applied to establish face and content validity of the Dementia Carer Assessment of Support Needs Tool (DeCANT) using Content Validity Index among experts and cognitive interviews with carers. Field-testing of DeCANT among carers included using the 12-item Short Form Health Survey, the Barthel-20 Index, and the Neuropsychiatric Inventory.

Results: Initially, an item pool of 63 items was generated, and pilot testing reduced this to 42 items. Subsequent field-testing resulted in a 25-item version of DeCANT, and confirmatory factor analysis of three hypothesized models demonstrated a marginally better fit to a four-factor model with fit indices of: $\chi^{2}=775.170(p<0.001)$, root mean square error of approximation $=0.073$, Comparative Fit Index $=0.946$, the Tucker-Lewis Index $=$ 0.938 , and weighted root mean residual $(\mathrm{WRMR})=1.265$.

Conclusions: DeCANT is a 25-item carer-reported questionnaire that can be used to help identify their support needs when caring for a person with dementia to enable supportive interventions and improve carers' health and well-being.

Key words: Alzheimer's disease, assessment, carer, dementia, informal caregiver, instrument, questionnaire, support needs

\section{Introduction}

Dementia is an illness that affects multidimensional aspects of daily living (Prince et al., 2015), not just for the individual with dementia but also for the

Correspondence should be addressed to: Trine Holt Clemmensen, M.H.Sc., Health Sciences Research Centre, UCL University College, Niels Bohrs Allé 1, DK5230 Odense M, Denmark. Email: thcl@ucl.dk. Received 27 Mar 2020; revision requested 08 May 2020; revised version received 03 Jul 2020; accepted 21 Jul 2020. First published online 03 Sep 2020 family and friends providing care (Giebel et al., 2019). Caring for a person with dementia is associated with poor mental, physical, and social health of the carer (Brodaty and Donkin, 2009; Schulz and Sherwood, 2008). It is therefore important to consider how carers are best supported in their caring role to preserve their health and well-being, and subsequently the health and well-being of the person with dementia (Jackson and Browne, 2017). From a societal perspective, supporting carers may 
postpone the need for formal care, including institutionalization, thereby significantly reducing costs (Jakobsen et al., 2011).

Carers report having unmet needs for support (Handels et al., 2018), and at the same time they are hesitant to use the formal supportive services available (Kerpershoek et al., 2019; Neville et al., 2015). The reported paradox of carers only being able to recognize their own needs retrospectively (Boots et al., 2015; McCabe et al., 2016) may explain why carers experience a lack of supportive interventions. Carers report multiple needs when caring, such as maintaining a good relationship to the person with dementia, psychoeducation, and learning coping strategies (Queluz et al., 2019). Also, carers have a need for respite, formal, and peer support (McCabe et al., 2016).

Recently, a review suggests that a better understanding of carers' needs is needed to develop effective supportive services (Queluz et al., 2019). In the context of health and social care, a systematic and holistic approach does not currently exist to assess carers' needs for support. A holistic approach when organizing interventions implies that needs assessment and goal-setting precede any intervention and that interventions be evaluated in accordance with this (Wade, 2016). Therefore, a logical first step would be to develop an instrument to assess carers' needs for support taking the physical, mental, and social threats to health and well-being into consideration before initiating targeted supportive interventions.

Systematic reviews (Mansfield et al., 2017; Novais et al., 2017) of existing instruments assessing dementia carers' needs show only one instrument to be psychometrically robust - the Carers' Needs Assessment for Dementia (CNA-D) (Wancata et al., 2005). However, the CNA-D is developed for research purposes only and is not feasible for use in clinical settings, because it relies on a 1-hour long professional interview. Another review also concludes that existing measures fail to take into account a conceptual framework developed for use in the context of carers focusing on both their carer role and the impact that their caring has on their well-being (Bangerter et al., 2019).

Carers' needs for support change throughout the disease trajectory of the person with dementia (Novais et al., 2017), and regular assessments are necessary to comply with the ever-changing challenges of daily living with dementia. It is therefore of paramount importance that any new instrument be feasible, easy to use, and support the communication between the professional and the carer in order to give the right support at the right time. In addition, developing an instrument to assess the support needs of carers requires a comprehensive approach recognizing the multidimensional aspects of caring (McCabe et al., 2016; Tatangelo et al., 2018).

The aim of this study was to develop a selfreported questionnaire for carers to assess their support needs in caring for a person with dementia, which may be used collaboratively between carers and health and social care professionals throughout the disease trajectory and across settings. The objectives were to: (1) generate items, (2) pilot test a version of the questionnaire, and (3) fieldtest the questionnaire before further validation.

\section{Methods}

A self-reported questionnaire was developed following the procedures outlined by de Vet et al. (2011). First, the construct to be measured and the target population were defined. Next, items were formulated and scoring of items was considered. Finally, several steps of pilot and field-testing were conducted.

\section{Conceptual model}

A person-centered approach, as reflected in the Biopsychosocial Model, was used as a conceptual model to define carers' support needs, as physical, psychological, and social (Engel, 1977; Wade and Halligan, 2017). Support needs arise in response to carers' functioning and ability to maintain health and well-being in daily life (Wade, 2015). Based on this, the new instrument was assumed to be multidimensional, comprising reflective items (de Vet et al., 2011).

\section{Item generation}

An item pool was generated based on the results of a scoping review of carers' support needs (unpublished data) and by qualitative interview findings. The interviews comprised interviews with carers $(n=23)$ and professionals $(n=13)$ in primary and secondary care. For details of the interviews, see Clemmensen et al. (2020). The scoping review followed the methodology described by Levac et al. (2010). The search was carried out between January 2007 and October 2019, and a total of 4651 articles were identified in PsycINFO, CINAHL, PubMed, and EMBASE. Three independent researchers selected 122 articles, and inductive content analysis was used to synthesize key concepts of carers' support needs (Elo and Kyngas, 2008). To ensure comprehensiveness of support needs, items were generated for each sub-category identified in the review and the interviews by the authors. Words were carefully selected to reproduce carers' own language, and item generation, reorganization, and reduction were an ongoing process. 
A four-point response scale of: No (not relevant) need met), Yes, a little more, Yes, quite a bit more, and Yes, very much more was developed with inspiration from the Carer Support Needs Assessment Tool (Ewing et al., 2013). This was chosen to enable respondents to assess the relevance and importance of their support needs, not just the existence of a need.

\section{Pilot testing}

An iterative process of pilot testing in different care settings was applied to strengthen generalizability to relevant care settings.

\section{Pilot Test 1}

The first draft of the Dementia Carer Assessment of Support Needs Tool (DeCANT) was evaluated with the Content Validity Index (CVI) among a panel of experts to ensure comprehensiveness and comprehensibility (Artino et al., 2014; Polit et al., 2007). Criteria for selection of experts were representative of dementia carers in general, or professionals in the area of dementia from different professions and from different care settings.

Using a CVI for items (I-CVI), the members of the expert panel were asked to independently evaluate representativeness, relevance, and clarity of the items on a scale ranging from $1=$ Not relevant to $4=$ Highly relevant (Polit et al., 2007). The experts were also given the opportunity of free text commenting.

To calculate I-CVIs, the ordinal scale was dichotomized into relevant (ratings 3-4) and not relevant (ratings 1-2) and the proportion of experts in agreement with respect to relevance was calculated, and kappa statistics were used to measure agreement (Polit et al., 2007). I-CVIs with kappa above 0.75 were considered excellent agreement (Cicchetti and Sparrow, 1981; Fleiss et al., 2003), and items with low I-CVI and a kappa below 0.75 were evaluated for adjustment or removal based on experts' agreement and free text comments.

\section{Pilot Test 2}

Cognitive interviewing was used to pilot test prospective participant's responses to DeCANT (Artino et al., 2014). Purposive sampling (Bernard, 2017) was conducted in collaboration with health professionals in primary and secondary care settings based on the following criteria: (1) provide help to a person with dementia on a regular basis because of a personal relationship rather than financial compensation, (2) able to communicate in Danish, and (3) $>18$ years old.

A combination of verbal probing and think-aloud techniques were used in the interviews (Artino et al., 2014; de Vet et al., 2011). While filling out the instrument, participants were asked to think aloud which was followed by questions concerning comprehensibility, relevance, completeness, acceptability, and feasibility.

The qualitative data were analyzed using deductive content analysis (Elo and Kyngas, 2008; Graneheim et al., 2017) to get an understanding of how participants interpret items.

Pilot Test 3

Due to both electronic and paper distribution in the following field-test, a supplementary pilot test was conducted to test the feasibility of an electronic version. REDCap electronic data capture hosted at the Odense Patient data Explorative Network, Odense University Hospital, Denmark was used for electronic data collection and management (Harris et al., 2019). Participants were purposively sampled (Bernard, 2017) to meet different criteria of age range, educational background, and use of electronic devices (PC, tablet, or mobile phone). An e-mail with a link to the electronic version of DeCANT was sent and participants were asked to comment on comprehensibility and feasibility. Participants highlighting problems were asked to participate in a short telephone interview.

\section{Field-test}

A field-test was carried out to reduce the number of items and examine the structural validity of DeCANT.

\section{Participants}

Sample size was determined based on seven cases per item and a minimum of 100 participants (de Vet et al., 2011). A heterogeneous sample of carers was recruited by purposive sampling (Bernard, 2017) to achieve a study population representative of carers in different care settings and levels of progression of dementia in the person cared for. Inclusion criteria were the same as in Pilot Test 2. Participants were recruited from (1) nine municipalities in Denmark, (2) one dementia clinic in a hospital, and (3) social media.

\section{Scoring issues}

A profile of carers' support needs was created by summing responses for each subscale with $N o=0$, Yes, a little more $=1$, Yes, quite a bit more $=2$, and Yes, very much more $=3$.

\section{Instruments}

In addition to DeCANT, the following instruments were used to describe participants and the person cared for: 
The 12-item Short Form Health Survey (SF-12) gathered information on carers' general health and well-being. The SF-12 measures eight domains of physical and mental health (Christensen et al., 2013). A summary of physical (PCS) and mental health (MCS) components was calculated as a $T$-score ranging from 0 to 100 with 100 reflecting better health. The Danish version has shown an acceptable fit in a confirmatory factor analysis (CFA) with the Comparative Fit Index $(\mathrm{CFI})=$ 0.939 and the root mean square error of approximation $($ RMSEA $)=0.115$. Also, Cronbach's $\alpha$ for PCS and MCS scores was 0.90 and 0.85 , respectively (Christensen et al., 2013).

The Barthel-20 Index (Barthel-20) consisted of 10 items to screen the level of functioning in activities of daily living in the person with dementia, and the carers filled out the questionnaire to the best of their ability (Collin et al., 1988; Maribo et al., 2006). Barthel-20 was scored 0-20, with 20 representing independence in daily activities. With an inter-rater reliability of intraclass correlation coefficient (ICC) = 0.95-0.97, Barthel-20 is considered reliable for use among older people (Sainsbury et al., 2005).

The Neuropsychiatric Inventory Questionnaire (NPI-Q) measured cognitive and functional decline in the person with dementia. The NPI-Q assesses severity of symptoms and also carers' distress based on 10 items asking about neuropsychiatric symptoms such as apathy and agitation (Kørner et al., 2008; Kaufer et al., 2000). Severity was scored 0-36, with 36 representing high severity. Distress was scored 0-60, with 60 representing high distress. Test-retest reliability for the severity and distress subscales is 0.8 and 0.94 , respectively. Furthermore, validity testing of the subscales shows correlations with the original NPI of 0.91 and 0.92 , respectively (Kaufer et al., 2000).

Follow-up by telephone and e-mail was done after 4-6 weeks if participants did not respond.

\section{Statistical analysis}

Descriptive characteristics of carers were collected regarding carers' age, residence, education, employment, and time spent caring. Also, information concerning the person with dementia was collected, for example, specific diagnosis, the extent to which the person with dementia was affected by the disease in general, and their utilization of formal care. Frequencies, frequency distributions, mean, median, standard deviation, and interquartile range were calculated for categorical and numerical variables.

\section{Item score distribution}

Frequencies of the responses were inspected at item level to consider whether all responses were informative and to evaluate the redundancy of items where a large proportion of participants chose the same response resulting in less discriminative power (de Vet et al., 2011).

\section{Partial inter-item correlation}

The relationship between items was examined using partial correlation to promote retention of unambiguous items in DeCANT (Marais and Andrich, 2008). Partial correlation between items should approach zero. Therefore, item pairs with partial correlation above 0.3 (van der Velde et al., 2009) were closely scrutinized, and items were dropped if content overlap was considered large and therefore redundant (Streiner et al., 2015).

\section{Confirmatory factor analysis}

Two four-factor models and one post hoc analysis model were hypothesized to reflect the multidimensionality of carers' support needs.

Model 1

Initial grouping of items was guided by a conceptual framework of four main categories derived from an inductive analysis of carers' and professionals' views on carers' support needs (Clemmensen et al., 2020). Carers' support needs were categorized into: (1) communicating and interacting with surroundings (i33, i37, i38, i41, and i42), (2) daily life when caring for a person with dementia (i1, i3, i4, i6, and i9), (3) maintaining own well-being (i22, i23, i24, i26, i27, i28, i30, i31, and i32), and (4) focusing on themselves (i12, i13, i16, i18, i19, and i21).

\section{Model 2}

The International Classification of Functioning (ICF) (World Health Organization, 2001) is based on the Biopsychosocial Model (Engel, 1977) and has been suggested as a framework to identify carers' support needs (World Health Organization, 2001). The ICF reflects a dynamic relationship between components of carers' functioning and contextual factors when caring. Linking rules described by Cieza et al. (2016) were used to categorize items into a first-level ICF category: (1) environmental factors (i1, i21, i22, i26, i33, i37, i38, i41, and i42), (2) activity and participation components (i3, i4, i6, i23, i28, i30, i31, and i32), (3) personal factors (i9, $\mathrm{i} 12$, i13, and i27), and (4) body structure/function components (i16, i18, i19, and i24).

Post hoc analysis of Model 2

The theoretical framework of ICF defining Model 2 is likely to be a stronger model to describe the dimensionality of carers' support needs, because it 


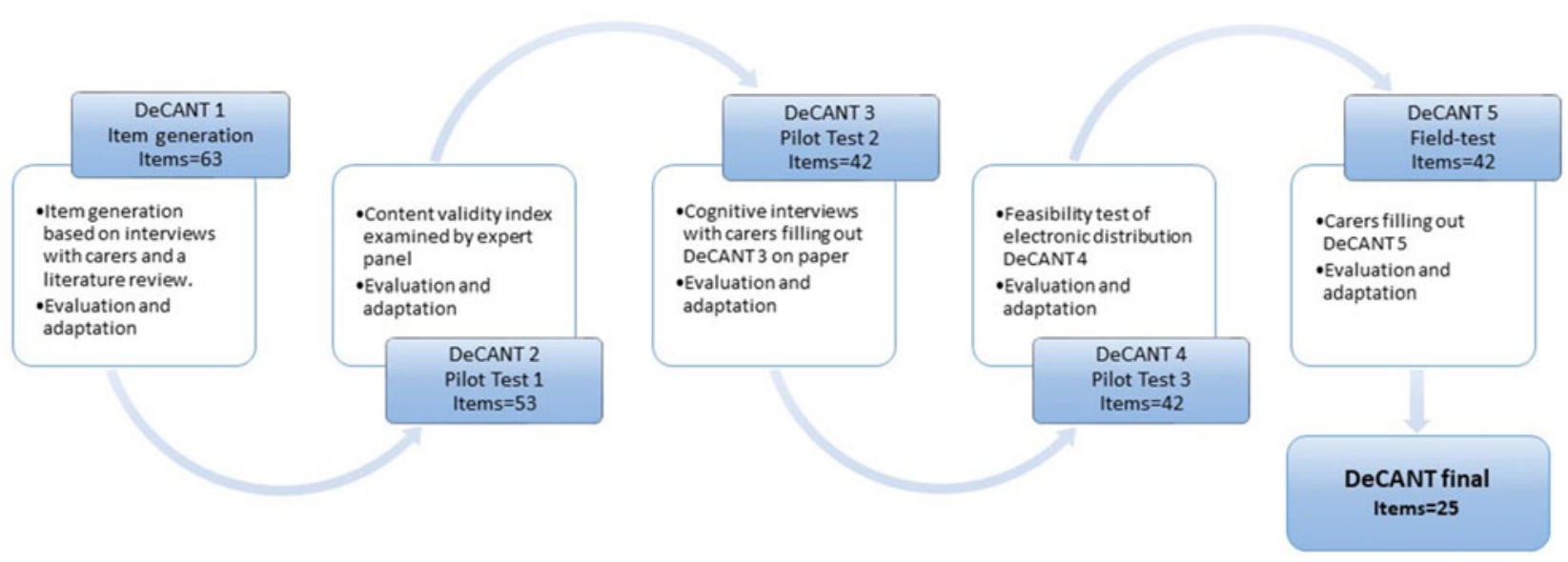

Figure 1. Flowchart of the development process of DeCANT from item generation to final version.

explains the interaction of factors under the construct to be measured. In classical test theory, local independence is implicitly assumed (Henning, 1989). Consequently, an inaccurate model may be hypothesized if local dependency exists, and it was checked whether this assumption was fulfilled. If it was not, the corresponding items were allowed to correlate to take this local dependence into account, resulting in a third model.

CFA was used to assess the fit of the hypothesized models. Since the items were categorical, all models were fitted using weighted least square mean and variance estimation (Muthén and Muthén, 1998-2017). The goodness of fit of the model to the data was evaluated using five criteria: the chi-squared test $\left(\chi^{2}\right)$ including degrees of freedom (df) and $p$-values, the weighted root mean residual (WRMR), the RMSEA, the Tucker-Lewis Index (TLI), and the CFI (Schreiber et al., 2006). Schreiber et al.'s guidelines were followed to indicate a close model fit for categorical data: $\chi^{2}$ with non-significant $p$-values, WRMR $<0.90, \mathrm{RMSEA}<$ $0.06, \mathrm{TLI}>0.95$, and CFI $>0.95$ (Schreiber et al., 2006).

Local dependency within Model 2 was checked by calculating partial correlations (Greene, 2018), and values $>0.3$ indicated possible local dependency between items (van der Velde et al., 2009). Furthermore, modification indices and standardized residuals were looked at to see whether they suggested any improvements to the estimated model (Boateng et al., 2018; Schreiber et al., 2006).

Internal consistency was calculated for each subscale in the three models using Cronbach's $\alpha$.

Data were analyzed with Stata 15 IC (StataCorp, College Station, TX, USA), RUMM2030 (RuMM Laboratory P/L, Duncraig, WA, Australia), and Mplus version 7.0 (Muthén and Muthén, 1998-2017).

\section{Ethical considerations}

All participants gave their informed written consent, and the study was registered with the Danish Data Protection Agency (2015-57-0016-020a). According to Danish law, ethics committee approval was not required (Ministry of Health and the Elderly, 2017).

\section{Results}

\section{Item generation}

Initially, 63 items were generated reflecting carers' support needs. All items started with: "Consider your present situation caring for the person with dementia. Do you have a need for support..." followed by the specific support need, for example, "to maintain your social network?" (item 4). Next, redundant items with similar wording and content were removed leaving a pool of 53 items. Figure 1 illustrates the development process of the DeCANT.

\section{Pilot testing}

In Pilot Test 1, eight experts (1 carer, 1 NGO consultant, 2 nurses, $1 \mathrm{MD}, 1$ psychologist, 1 physiotherapist, and 1 occupational therapist) rated the DeCANT using the CVI. I-CVIs ranged from 0.50 to 1.00 with kappa values from fair to excellent (see Supplementary Material Appendix 1). Items with I-CVI $<0.78$ (17 items) were more closely scrutinized by considering expert comments. This resulted in replacing some words and removing 11 items. For example, the item "Do you have a need for support to get better opportunities to carry out daily activities?" was removed as experts found it less relevant and difficult to understand in addition to a low I-CVI (0.63).

In Pilot Test 2, 12 carers of a person with dementia participated in cognitive interviews. Participants 
comprised a heterogeneous group of carers from different care settings (the person with dementia was: (1) living at home $n=4,(2)$ living in a nursing home $n=6$, (3) deceased $n=2$ ) and with varying relationships to the person cared for (2 brothers, 5 wives, 3 daughters, 1 ex-wife, and 1 husband).

The participants spent 10-25 minutes answering DeCANT. Some found the item on sexuality inappropriate and the word "intimacy" was used instead. Furthermore, the item "Do you have a need for support to be involved as an important collaborator in this collaborative caring work?" (item 37) was found to be offending, because the carer assumed that he/she was an important collaborator. The item was changed to "Do you have a need for support to be involved in this collaborative caring work?"

In Pilot Test 3, the electronic version was tested on 10 different electronic devices by 7 participants. Follow-up telephone interviews were conducted with three participants to elucidate difficulties. In general, participants found items and response options understandable, and they were able to fill out DeCANT without having questions or comments.

In summary, the pilot tests resulted in a 42 -item version of DeCANT, which was used in the field-test.

\section{Field-test}

In total, 434 carers were invited to participate. Three-hundred-and-one participants $(69.35 \%)$ filled in the field-test version of the DeCANT on paper $(19.93 \%)$ or electronically $(80.07 \%)$. The sample comprised carers with different relationships to the person cared for and different sociodemographic backgrounds (Table 1). The largest group of carers consisted of women and spouses of a person with Alzheimer's disease, though other types of carers were also represented.

\section{Item score distribution}

In general, participants used all response categories and a maximum of $1 \%$ of the scores were missing per item. The most frequently used response category for almost all items was No (not relevant/met need). Also, distribution of item scores showed that three items (i24, i29, and i39) had a very high proportion of participants choosing the same response option yielding a right skewed distribution (Table 2).

\section{Partial inter-item correlation}

We found 41 instances with high partial correlation between item pairs $(>0.3)$. Each item pair was closely scrutinized for content overlap, item score distributions, and the findings from the cognitive interviews, and this information was used to decide whether both items or only one item should be
Table 1. Demographic characteristics of participants in the field-testing phase (total $n=301$ )

\begin{tabular}{|c|c|c|}
\hline \multicolumn{3}{|l|}{ VARIABLE } \\
\hline Sex (female), $n(\%)$ & 236 & $(78.41)$ \\
\hline Age (years), mean (SD) & 61.7 & $(13.68)$ \\
\hline \multicolumn{3}{|l|}{ Relation to person with dementia, $n(\%)$} \\
\hline Spouse/partner & 161 & $(53.67)$ \\
\hline Child & 123 & $(41.00)$ \\
\hline Sibling & 2 & $(0.67)$ \\
\hline Other & 14 & $(4.67)$ \\
\hline \multicolumn{3}{|l|}{ Education, $n(\%)$} \\
\hline Elementary education & 21 & $(7.22)$ \\
\hline Secondary education & 112 & $(38.49)$ \\
\hline Higher education & 139 & $(47.77)$ \\
\hline Other & 19 & $(6.53)$ \\
\hline \multicolumn{3}{|l|}{ Employment, $n(\%)$} \\
\hline Paid employment & 121 & $(40.88)$ \\
\hline Unemployed/retired & 161 & $(54.39)$ \\
\hline Other (e.g. sick leave) & 14 & $(4.73)$ \\
\hline \multicolumn{3}{|l|}{ Residential status, $n(\%)$} \\
\hline Co-resident with person with dementia & 128 & $(42.52)$ \\
\hline Resides away from person with dementia & 168 & $(55.81)$ \\
\hline \multicolumn{3}{|l|}{ Living in the same municipality, $n(\%)$} \\
\hline Same municipality & 212 & $(70.90)$ \\
\hline Different municipalities & 87 & $(29.10)$ \\
\hline \multicolumn{3}{|l|}{ SF-12 carer, mean (SD) } \\
\hline Physical health component & 49.49 & $(11.29)$ \\
\hline Mental health component & 44.43 & $(12.59)$ \\
\hline \multicolumn{3}{|l|}{ Diagnosis of person with dementia, $n(\%)$} \\
\hline Alzheimer's disease & 198 & $(67.35)$ \\
\hline Frontotemporal dementia & 17 & $(5.78)$ \\
\hline Lewy body dementia & 14 & $(4.76)$ \\
\hline Vascular dementia & 13 & $(4.42)$ \\
\hline Mixed dementia diagnosis & 14 & $(4.76)$ \\
\hline Other & 23 & $(7.82)$ \\
\hline Do not know & 15 & $(5.10)$ \\
\hline $\begin{array}{l}\text { Barthel-20 person with dementia, median } \\
\text { (IQR) }\end{array}$ & 18 & $(6)$ \\
\hline \multicolumn{3}{|l|}{ NPI-Q, median (IQR) } \\
\hline Severity & 6 & $(7)$ \\
\hline Distress & 7 & (10) \\
\hline \multicolumn{3}{|l|}{ Impact of dementia rated by carer, $n(\%)$} \\
\hline None & 3 & $(1.01)$ \\
\hline Low & 34 & $(11.45)$ \\
\hline Moderate & 153 & $(51.52)$ \\
\hline Severe & 100 & $(33.67)$ \\
\hline Do not know & 7 & $(2.36)$ \\
\hline
\end{tabular}

$\mathrm{IQR}$, interquartile range.

retained. Altogether, 17 items were removed (i2, i5, i7, i8, i10, i11, i14, i15, i17, i20, i25, i29, $\mathrm{i} 34, \mathrm{i} 35, \mathrm{i} 36, \mathrm{i} 39$, and i40) resulting in a final 25-item version of the DeCANT.

\section{Confirmatory factor analysis}

The factor structure of the 25-item version of the DeCANT was investigated by CFA. 
Table 2. Presentation of the 42 items in the DeCANT version 5 and item score distribution in the field-testing of the DeCANT version 5

\begin{tabular}{|c|c|c|c|c|c|c|c|c|c|c|c|}
\hline \multirow{2}{*}{$\begin{array}{l}\text { ITEM } \\
\# \\
\ldots \ldots \ldots \ldots \ldots . . \\
\text { i1 }\end{array}$} & \multirow{2}{*}{$\begin{array}{l}\text { ITEMS IN DECANT VERSION } 5 \\
\text { CONSIDER YOUR PRESENT SITUATION CARING FOR THE PERSON WITH } \\
\text { DEMENTIA. DO YOU HAVE A NEED FOR SUPPORT ... } \\
\text { to make sure that services targeted the person with dementia conform to } \\
\text { your daily life? }\end{array}$} & \multirow{2}{*}{$\begin{array}{c}n \\
298\end{array}$} & \multirow{2}{*}{$\begin{array}{c}\text { MISSING } \\
3\end{array}$} & \multicolumn{2}{|c|}{$\begin{array}{c}\text { No (NOT } \\
\text { ELEVANT/NEED } \\
\text { MET), } n(\%)\end{array}$} & \multicolumn{2}{|c|}{$\begin{array}{l}\text { YES, A LITTLE } \\
\text { MORE, } n(\%)\end{array}$} & \multicolumn{2}{|c|}{$\begin{array}{c}\text { YES, QUITE } \\
\text { A BIT MORE, } \\
n(\%)\end{array}$} & \multicolumn{2}{|c|}{$\begin{array}{c}\text { YES, VERY } \\
\text { MUCH } \\
\text { MORE, } n(\%)\end{array}$} \\
\hline & & & & 150 & $(50.3)$ & 89 & $(29.9)$ & 36 & $(12.1)$ & 23 & $(7.7)$ \\
\hline i2 & for activities to the person with dementia & 298 & 3 & 116 & $(38.9)$ & 107 & $(35.9)$ & 45 & $(15.1)$ & 30 & $(10.1)$ \\
\hline i3 & to manage everyday chores (e.g. dressing, cleaning, transportation)? & 298 & 3 & 190 & $(63.8)$ & 62 & $(20.8)$ & 26 & $(8.7)$ & 20 & $(6.7)$ \\
\hline i4 & to maintain your social network? & 299 & 2 & 178 & $(59.5)$ & 60 & $(20.1)$ & 39 & $(13.0)$ & 22 & $(7.4)$ \\
\hline i5 & to transportation of the person with dementia (e.g. to the GP, hairdresser etc.)? & 299 & 2 & 193 & $(64.5)$ & 51 & $(17.1)$ & 33 & $(11.0)$ & 22 & $(7.4)$ \\
\hline i6 & $\begin{array}{l}\text { to manage changed behaviour in the person with dementia (e.g. aggressive, } \\
\text { restless or passive behaviour)? }\end{array}$ & 299 & 2 & 118 & $(39.5)$ & 95 & $(31.8)$ & 54 & $(18.1)$ & 32 & $(10.7)$ \\
\hline i7 & to improve your communication skills in relation to the person with dementia? & 298 & 3 & 129 & $(43.3)$ & 99 & $(33.2)$ & 44 & $(14.8)$ & 26 & $(8.7)$ \\
\hline i8 & to manage the person with dementia's loss of memory? & 298 & 3 & 100 & $(33.6)$ & 126 & $(42.3)$ & 49 & $(16.4)$ & 23 & $(7.7)$ \\
\hline i9 & to manage person with dementia's lack of disease awareness? & 299 & 2 & 102 & $(34.1)$ & 105 & $(35.1)$ & 54 & $(18.1)$ & 40 & $(13.4)$ \\
\hline i10 & to solve problems in everyday life with the person with dementia? & 299 & 2 & 94 & $(31.4)$ & 116 & $(38.8)$ & 61 & $(20.4)$ & 28 & $(9.4)$ \\
\hline i11 & to get information on assistive aids (e.g. assistive technologies)? & 299 & 2 & 117 & $(39.1)$ & 118 & $(39.5)$ & 41 & $(13.7)$ & 23 & $(7.7)$ \\
\hline i12 & to feel appreciated in what you are doing for the person with dementia? & 298 & 3 & 155 & $(52.0)$ & 75 & $(25.2)$ & 39 & $(13.1)$ & 29 & $(9.7)$ \\
\hline i13 & to ask for help for yourself? & 298 & 3 & 143 & $(48.0)$ & 84 & $(28.2)$ & 48 & $(16.1)$ & 23 & $(7.7)$ \\
\hline $\mathrm{i} 14$ & to get information on help and counselling for yourself? & 298 & 3 & 115 & $(38.6)$ & 94 & $(31.5)$ & 59 & $(19.8)$ & 30 & $(10.1)$ \\
\hline i15 & to accept supportive services for yourself? & 298 & 3 & 139 & $(46.6)$ & 92 & $(30.9)$ & 46 & $(15.4)$ & 21 & $(7.0)$ \\
\hline i16 & to cope with your own emotions (e.g. loss or grief)? & 299 & 2 & 98 & $(32.8)$ & 91 & $(30.4)$ & 68 & $(22.7)$ & 42 & $(14.0)$ \\
\hline i17 & to cope with everyday worries? & 299 & 2 & 110 & $(36.8)$ & 113 & $(37.8)$ & 50 & $(16.7)$ & 26 & $(8.7)$ \\
\hline i18 & to manage stress? & 298 & 3 & 145 & $(48.7)$ & 79 & $(26.5)$ & 41 & $(13.8)$ & 33 & $(11.1)$ \\
\hline i19 & to deal with bad conscience or guilt? & 299 & 2 & 125 & $(41.8)$ & 79 & $(26.4)$ & 52 & $(17.4)$ & 43 & $(14.4)$ \\
\hline $\mathrm{i} 20$ & to get information on challenges that may occur in the progression of dementia? & 299 & 2 & 84 & $(28.1)$ & 127 & $(42.5)$ & 60 & $(20.1)$ & 28 & $(9.4)$ \\
\hline $\mathrm{i} 21$ & to prepare for deterioration of the situation (e.g. moving into nursing home)? & 299 & 2 & 95 & $(31.8)$ & 97 & $(32.4)$ & 67 & $(22.4)$ & 40 & $(13.4)$ \\
\hline $\mathrm{i} 22$ & to get respite from everyday caring? & 299 & 2 & 181 & $(60.5)$ & 83 & $(27.8)$ & 23 & $(7.7)$ & 12 & $(4.0)$ \\
\hline $\mathrm{i} 23$ & to prioritize your own health? & 299 & 2 & 175 & $(58.5)$ & 72 & $(24.1)$ & 34 & $(11.4)$ & 18 & $(6.0)$ \\
\hline $\mathrm{i} 24$ & to sleep better? & 299 & 2 & 201 & $(67.2)$ & 50 & $(16.7)$ & 33 & $(11.0)$ & 15 & $(5.0)$ \\
\hline $\mathrm{i} 25$ & to get more time for yourself? & 299 & 2 & 161 & $(53.8)$ & 84 & $(28.1)$ & 39 & $(13.0)$ & 15 & $(5.0)$ \\
\hline i26 & to get in contact with others in the same situation as you? & 299 & 2 & 165 & $(55.2)$ & 92 & $(30.8)$ & 32 & $(10.7)$ & 10 & (3.3) \\
\hline $\mathrm{i} 27$ & to feel confident in the caring role? & 299 & 2 & 148 & $(49.5)$ & 101 & $(33.8)$ & 38 & $(12.7)$ & 12 & $(4.0)$ \\
\hline $\mathrm{i} 28$ & to make decisions regarding the person with dementia? & 299 & 2 & 169 & $(56.5)$ & 87 & $(29.1)$ & 34 & $(11.4)$ & 9 & $(3.0)$ \\
\hline $\mathrm{i} 29$ & to maintain a good relationship with the person with dementia? & 299 & 2 & 199 & $(66.6)$ & 71 & $(23.7)$ & 24 & $(8.0)$ & 5 & $(1.7)$ \\
\hline $\mathrm{i} 30$ & to create nice experiences together with the person with dementia? & 299 & 2 & 158 & $(52.8)$ & 95 & $(31.8)$ & 36 & $(12.0)$ & 10 & $(3.3)$ \\
\hline i31 & to share the responsibility of caring with someone else? & 299 & 2 & 131 & $(43.8)$ & 102 & $(34.1)$ & 51 & $(17.1)$ & 15 & $(5.0)$ \\
\hline $\mathrm{i} 32$ & to talk to someone about intimacy? & 298 & 3 & 179 & $(60.1)$ & 83 & $(27.9)$ & 25 & $(8.4)$ & 11 & (3.7) \\
\hline $\mathrm{i} 33$ & to get information about who to contact for support? & 300 & 1 & 161 & $(53.7)$ & 80 & $(26.7)$ & 38 & $(12.7)$ & 21 & $(7.0)$ \\
\hline $\mathrm{i} 34$ & to get information on what services professionals (e.g. nurse) may offer? & 300 & 1 & 160 & $(53.3)$ & 89 & $(29.7)$ & 28 & $(9.3)$ & 23 & $(7.7)$ \\
\hline
\end{tabular}




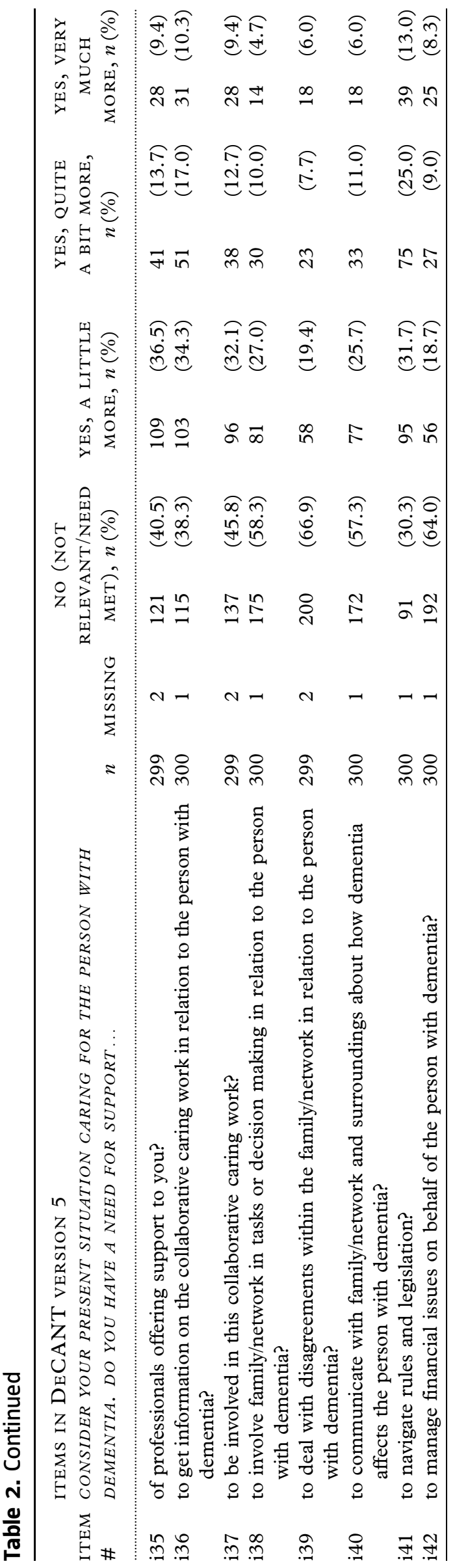

Model 1

The 25 items were distributed, conforming to the four main categories guiding the structure of DeCANT: (1) communicating and interacting with surroundings (five items), (2) daily life when caring for a person with dementia (five items), (3) maintaining own well-being (nine items), and (4) focusing on themselves (six items). All items had reasonable factor loadings ranging between 0.50 and $0.88(p<0.001)$ and factor correlations ranging between 0.72 and 0.92 . Fit indices for the model are represented in Table 3 and show a moderate fit.

Model 2

The 25 items were each linked to a first level ICF category: (1) environmental factors (nine items), (2) activity and participation components (eight items), (3) personal factors (four items), and (4) body structure/function components (four items). Factor loadings of items to the corresponding factor ranged between 0.47 and $0.92(p<0.001)$ and factor correlations ranged between 0.75 and 0.99 . Further, analysis showed estimates of goodness of fit resembling the estimates of Model 1 (see Table 3).

Post hoc analysis of Model 2

Possible local dependency was found between four item pairs (i1 and i22, i16 and 18, i16 and i19, and i41 and i42), and these items were allowed to correlate in this post hoc model as an addition to Model 2. CFA resulted in some improvement in all fit indices compared with Models 1 and 2 with estimates of $\chi^{2}=775.170(p<0.001)$, RMSEA $=$ $0.073, \mathrm{CFI}=0.946$, TLI $=0.938$, and $\mathrm{WRMR}=$ 1.265 (Table 3). Factor loadings of the improved model ranged between 0.47 and $0.91 \quad(p<0.001)$ and factor correlations ranged between 0.77 and 0.99 (Figure 2).

Inspection of modification indices and standardized residuals showed no indicators for improvement of the analyzed models.

Cronbach's $\alpha$ values for the subscales of Model 1 were $0.78,0.70,0.86$, and 0.86 . For Model 2 and post hoc analysis of Model 2, subscales' Cronbach's $\alpha$ values were $0.84,0.80,0.73$, and 0.84 .

\section{Discussion}

The need for a self-reported instrument to assess carers' support needs when caring for a person with dementia throughout the disease trajectory and across settings in health and social care has been addressed. Careful investigation of the literature and carers' and professionals' views on carers' support needs resulted in a 25 -item version of the DeCANT 
Table 3. CFA fit indices for the analyzed models, $n=298$

\begin{tabular}{|c|c|c|c|c|c|c|c|c|}
\hline & $\begin{array}{c}\text { CHI-SQUARED } \\
\left(\chi^{2}\right)\end{array}$ & $\begin{array}{l}\text { DEGREES OF } \\
\text { FREEDOM }\end{array}$ & $p$-VALUES & $\begin{array}{l}\text { RMSEA } \\
(90 \% \mathrm{CI})\end{array}$ & $\begin{array}{c}\text { PROBABILITY } \\
\text { RMSEA } \leq 0.05\end{array}$ & CFI & TLI & WRMR \\
\hline $\begin{array}{l}\text { Model 1: Four-factor } \\
\text { model based on } \\
\text { inductive categories }\end{array}$ & 833.447 & 269 & $<0.001$ & $\begin{array}{c}0.083 \\
(0.077-0.090)\end{array}$ & 0.000 & 0.934 & 0.927 & 1.342 \\
\hline $\begin{array}{l}\text { Model 2: Four-factor } \\
\text { model based on ICF } \\
\text { framework }\end{array}$ & 851.985 & 270 & $<0.001$ & $\begin{array}{c}0.084 \\
(0.078-0.091)\end{array}$ & 0.000 & 0.932 & 0.925 & 1.393 \\
\hline $\begin{array}{l}\text { Post hoc analysis of } \\
\text { Model } 2\end{array}$ & 775.170 & 266 & $<0.001$ & $\begin{array}{c}0.073 \\
(0.068-0.079)\end{array}$ & 0.000 & 0.946 & 0.938 & 1.265 \\
\hline
\end{tabular}

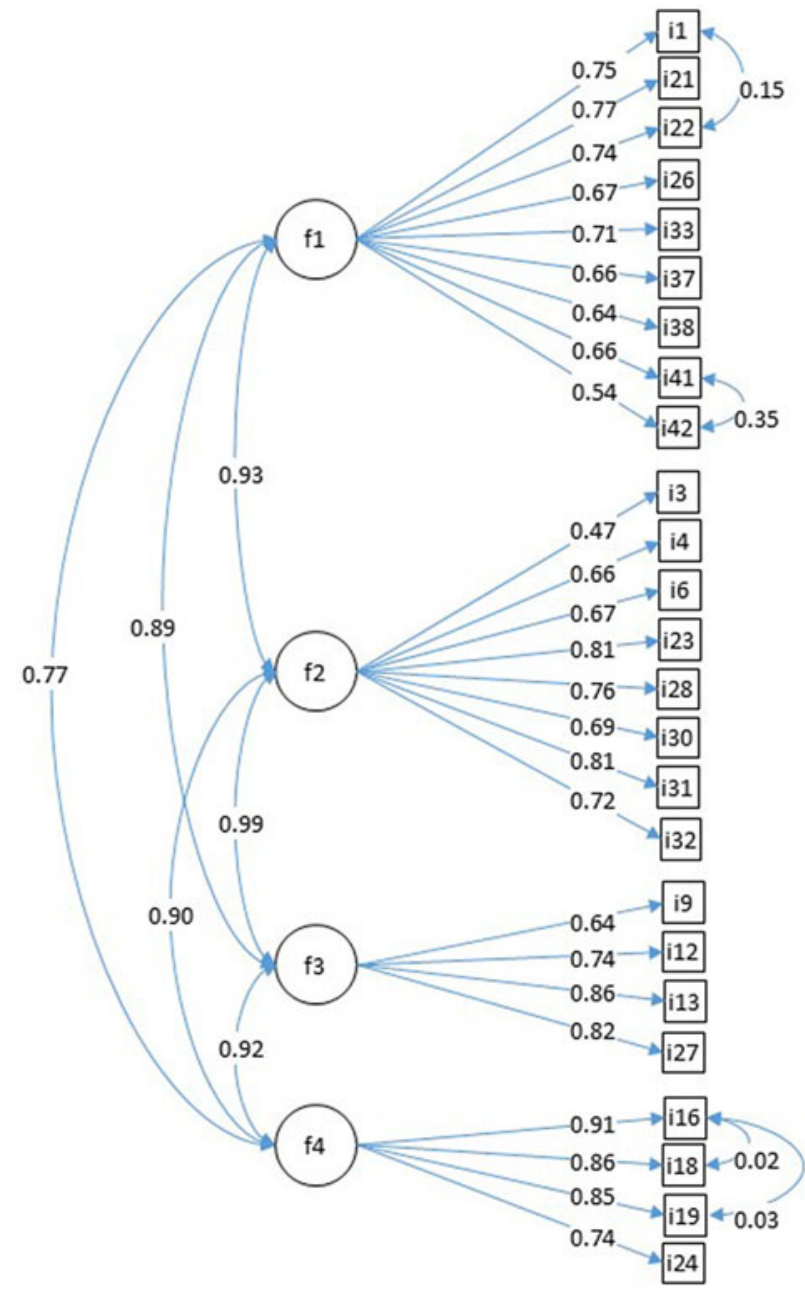

Figure 2. Diagram showing factor correlations and loadings of the post hoc analysis of Model 2 . The circles represent the four factors, that is, $f 1=$ factor 1 , and the squares represent items, that is, $\mathrm{i} 1=$ item 1 . The arrows between factors describe factor correlations. The arrows from factors to items describe item factor loadings. Arrows between items show their correlated error.

that measured four dimensions of carers' support needs regarding communication with surroundings, daily life, focusing on themselves, and their own well-being.
The Biopsychosocial Model (Engel, 1977; Wade and Halligan, 2017), used as an overall conceptual model to understand the complexity of carers' support needs, has its origin in the health sciences, which may seem inappropriate as caring in itself is not characterized as a health problem. However, caring has been shown to threaten carers' health, well-being, and functioning in daily life (Brodaty and Donkin, 2009; Schulz and Sherwood, 2008), and the Biopsychosocial Model allows for a personcentered and multidimensional way of identifying carers' support needs. Issues related to carers' social or psychological functioning are thus considered equal to potential physical disabilities (Engel, 1977; Wade and Halligan, 2017).

The construct of carers' support needs measured by DeCANT has required substantial work focused on maximizing the extent to which generated items reflect the support needs of the target population (de Vet et al., 2011). When assessing support needs, it is essential that carers' subjective views on what is helpful are emphasized as opposed to only those arising from professional judgment (Hjortbak and Johansen, 2011). However, including both views when generating items is important, because carers may not be able to acknowledge (Boots et al., 2015) and/or articulate (Stirling et al., 2010) all of their own needs. Furthermore, our response categories were specifically designed to reflect a personcentered approach (Sharma et al., 2015) respecting both subjective and professional views when assessing carers' support needs, because carers have to decide whether a support need is relevant to them or not, and if considered to be so, to assess the extent of needed support.

Content validity was investigated using several methods. In Pilot Test 1, a panel of experts assessed the comprehensiveness and comprehensibility of the first draft of DeCANT. However, the criteria used for selection of the expert panel members may have resulted in too much focus on professional judgment, and we therefore decided that items with I-CVI $<0.78$ were not automatically removed. 
Instead, removal of items was decided among the author team using information from both I-CVI and investigations preceding item generation to boost the carer's perspective. During the cognitive interviews in Pilot Test 2, carers pointed out that the sensitive content in DeCANT obligated professionals to follow up on identified needs. This is important when implementing DeCANT in future health and social care, because DeCANT in itself may start a dialogue between carers and professionals. Creating a trusting relationship with professionals is the most important facilitator of carers' use of supportive services (Stephan et al., 2018). Using DeCANT may therefore be a feasible way of facilitating a positive and balanced dialogue between carers and professionals.

Investigating the item score distributions revealed a floor effect in all items for the response category No (not relevant/met need). This was to be expected, as the response option contains different answers of "no." Designing the response category in this way may have caused problems discriminating carers' responses. However, the focus of DeCANT was to provide information that identified support needs: not why a carer did not have a need for support.

CFA of Model 1 and Model 2 demonstrated almost the same fit indices of a moderate fitting model. Post hoc analysis of Model 2 including possible local dependency showed a marginally improved fit and we believe this model to be the best fit when describing the factor structure of DeCANT, because it is based on a strong theoretical framework (Schreiber et al., 2006) taking into account the dynamic interaction of carers' support needs in the context of caring (Clemmensen et al., 2020). Although fit indices from post hoc analysis of Model 2 imply an acceptable fit of observed data, further testing of the factor structure should be performed in more and larger samples (Boateng et al., 2018; Hu and Bentler, 1999).

In the post hoc analysis of Model 2, all items demonstrated high factor loadings above 0.60 . Only one item (i3: "Do you have a need for support to manage everyday chores?") showed a lower loading of 0.47 , which was considered acceptable. This item differed from other items by containing information on support needs of the person with dementia, not the carer, indicating that the item may describe a latent trait different from that intended. Nevertheless, item 3 is an example of the inter-relatedness of carers' support needs in the context of caring as described by the theoretical framework. Thus, indirectly asking about the need for support in daily living from the person with dementia clarified if the carers' individual resources to manage care were balanced.
Subscales' inter-item correlations of the hypothesized models, all demonstrated satisfying internal consistency between 0.70 and 0.95 according to guidelines by Terwee et al. (2007).

\section{Using DeCANT}

In future health and social care, DeCANT, with its holistic and person-centered approach, may be used to identify carers' support needs. Carers' needs are complex, because they are affected by the support needs of the person cared for, the individual resources and priorities of the carers, as well as the context in which the caring occurs (Bangerter et al., 2019; McCabe et al., 2016). DeCANT was designed to enable an individually tailored and quick way of profiling support needs most important to carers in the specific context of caring. With only 25 items, carers' will be able to answer DeCANT in 10 minutes or less.

\section{Strength and limitations}

Heterogeneous sampling of carers was strived for in the field-testing of DeCANT to be applicable to the various settings intended for use. Nonetheless, participants were primarily female or spouses, which may reduce the representativeness of the sample. However, this seems to be a general pattern in dementia research when recruiting carers (Alzheimerforeningen, 2018). In contrast, the sample included a large proportion of non-spousal carers and carers reporting great variety of dementia severity in the person cared for, which suggests that the sample may be representative of various types of carers and caring contexts. However, the sampling has not considered different cultural attitudes towards the caring role. Therefore, the relevance of using DeCANT should be carefully considered in the cultural context (Nielsen et al., 2019).

A limitation of the study is the small sample size $(n=301)$. Larger samples with a larger participant/ item ratio of at least 10 participants per item are preferable in CFA (Boateng et al., 2018) as more stable factor loadings and lower measurement errors are obtained. Thus, replication of DeCANT's factor structure is necessary to ensure generalizability of the suggested structure in similar populations (Boateng et al., 2018).

Development of DeCANT followed a rigorous stepwise procedure for questionnaire development (de Vet et al., 2011). However, before using DeCANT in practice, further research is needed to examine its psychometric properties. Hence, we recommend investigation of its construct validity by comparing DeCANT with existing measures of carers' health and well-being and test-retesting of reliability as next steps. 


\section{Conclusion}

A 25-item self-reported instrument (DeCANT) to identify carers' support needs when caring for a person with dementia was developed. CFA demonstrated a moderate fit to a four-factor model assessing carers' support needs in relation to communication with surroundings, daily life, focusing on themselves, and their own well-being. DeCANT is suggested to be used (a) to help identify carers' support needs when caring for a person with dementia to enable supportive interventions in a timely manner; (b) to increase the awareness of carers' support needs to improve carers' health and wellbeing and, by extension, the person being cared for; and (c) as an outcome measure, to evaluate supportive interventions in everyday health and social care.

\section{Conflict of interest}

None.

\section{Description of authors' roles}

THC designed the study, carried it out, analyzed the data, and wrote the manuscript. HHL, HKK, and KAR contributed to the design, supervised the data collection and analysis, and assisted with critical revision of the paper.

\section{Acknowledgements}

This work was supported by UCL University College Denmark, The Danish Alzheimer Association, and The Association of Danish Physiotherapists. Also, the authors thank Jens Søndergaard, University Hospital of Aarhus, Denmark, for supervising the statistical analysis.

\section{Supplementary material}

To view supplementary material for this article, please visit https://doi.org/10.1017/S1041610220001714

\section{References}

Alzheimerforeningen. (2018). Livet med demens. Rapport om en spørgeskemaundersøgelse blandt pårørende til demenspatienter $i$ Danmark. København: Alzheimerforeningen.

Artino, A.R., Jr, La Rochelle, J.S., Dezee, K.J. and Gehlbach, H. (2014). Developing questionnaires for educational research: AMEE Guide No. 87.
Medical Teacher, 36, 463-474. doi: 10.3109/0142159X.2014 .889814 .

Bangerter, L.R., Griffin, J.M., Zarit, S.H. and Havyer, R. (2019). Measuring the needs of family caregivers of people with dementia: an assessment of current methodological strategies and key recommendations. Fournal of Applied Gerontology, 38, 1304-1318. doi: 10 .1177/0733464817705959.

Bernard, H.R. (2017). Research Methods in Anthropology: Qualitative and Quantitative Approaches. 6th ed. Lanham, MD: Rowman \& Littlefield.

Boateng, G.O., Neilands, T.B., Frongillo, E.A., Melgar-Quinonez, H.R. and Young, S.L. (2018). Best practices for developing and validating scales for health, social, and behavioral research: a primer. Frontiers in Public Health, 6, 149. doi: 10.3389/fpubh.2018.00149.

Boots, L.M., Wolfs, C.A., Verhey, F.R., Kempen, G.I. and de Vugt, M.E. (2015). Qualitative study on needs and wishes of early-stage dementia caregivers: the paradox between needing and accepting help. International Psychogeriatrics, 27, 927-936. doi: 10.1017/ S1041610214002804.

Brodaty, H. and Donkin, M. (2009). Family caregivers of people with dementia. Dialogues in Clinical Neuroscience, 11, 217-228.

Christensen, L.N., Ehlers, L., Larsen, F.B. and Jensen, M.B. (2013). Validation of the 12 item short form health survey in a sample from Region Central Jutland. Social Indicators Research, 114, 513-521. doi: 10.1007/s11205012-0159-9.

Cicchetti, D.V. and Sparrow, S.A. (1981). Developing criteria for establishing interrater reliability of specific items: applications to assessment of adaptive behavior. American fournal of Mental Deficiency, 86, 127-137.

Cieza, A., Fayed, N., Bickenbach, J. and Prodinger, B. (2016). Refinements of the ICF Linking Rules to strengthen their potential for establishing comparability of health information. Disability and Rehabilitation, 41, 1-10. doi: 10 .3109/09638288.2016.1145258.

Clemmensen, T.H., Lauridsen, H.H., AndersenRanberg, K. and Kristensen, H.K. (2020). 'I know his needs better than my own' - carers' support needs when caring for a person with dementia. Scandinavian fournal of Caring Sciences, 1-14. doi: 10.1111/scs.12875.

Collin, C., Wade, D.T., Davies, S. and Horne, V. (1988). The Barthel ADL Index: a reliability study. International Disability Studies, 10, 61-63. doi: 10.3109/ 09638288809164103.

de Vet, H.C., Terwee, C.B., Mokkink, L.B. and Knol, D.L. (2011). Measurement in Medicine: A Practical Guide, 1st ed. Cambridge: Cambridge University Press.

Elo, S. and Kyngas, H. (2008). The qualitative content analysis process. Fournal of Advanced Nursing, 62, 107-115. doi: 10.1111/j.1365-2648.2007.04569.x.

Engel, G.L. (1977). The need for a new medical model: a challenge for biomedicine. Science, 196, 129-136. doi: 10 $.1126 /$ science. 847460 .

Ewing, G., Grande, G. and National Association for Hospice at Home (2013). Development of a Carer Support Needs Assessment Tool (CSNAT) for end-of-life care practice at home: a qualitative study. Palliative Medicine, 27, 244-256. doi: 10.1177/0269216312440607. 
Fleiss, J.L., Levin, B. and Paik, M.C. (2003). Statistical Methods for Rates and Proportions. 3rd ed. Hoboken, NJ: John Wiley \& Sons.

Giebel, C.M., Davies, S., Clarkson, P., Sutcliffe, C., Challis, D. and HoSt-D (Home Support in Dementia) Programme Management Group. (2019). Costs of formal and informal care at home for people with dementia: 'expert panel' opinions from staff and informal carers. Dementia, 18, 210-227. doi: 10.1177/1471301216665705.

Graneheim, U.H., Lindgren, B.M. and Lundman, B. (2017). Methodological challenges in qualitative content analysis: a discussion paper. Nurse Education Today, 56, 29-34. doi: 10.1016/j.nedt.2017.06.002.

Greene, W.H. (2018). Econometric Analysis. 8th ed. New York: Pearson.

Handels, R.L. et al. (2018). Quality of life, care resource use, and costs of dementia in 8 European countries in a crosssectional cohort of the actifcare study. Fournal of Alzheimer's Disease, 66, 1027-1040. doi: 10.3233/JAD180275.

Harris, P.A. et al. (2019). The REDCap consortium: building an international community of software platform partners. Fournal of Biomedical Informatics, 95, 103208. doi: 10.1016/j.jbi.2019.103208.

Henning, G. (1989). Meanings and implications of the principle of local independence. Language Testing, 6, 95108. doi: 10.1177/026553228900600108.

Hjortbak, B.R. and Johansen, J.S. (Eds.) (2011). Challenges to Rehabilitation in Denmark. 1st ed. Aarhus: Rehabiliteringsforum Danmark.

Hu, L. and Bentler, P.M. (1999). Cutoff criteria for fit indexes in covariance structure analysis: conventional criteria versus new alternatives. Structural Equation Modeling: A Multidisciplinary fournal, 6, 1-55. doi: 10.1080/ 10705519909540118.

Jackson, G.A. and Browne, D. (2017). Supporting carers of people with dementia: what is effective? BfPsych Advances, 23, 179-186. doi: 10.1192/apt.bp.113.011288.

Jakobsen, M., Poulsen, P.B., Reiche, T., Nissen, N.P. and Gundgaard, J. (2011). Costs of informal care for people suffering from dementia: evidence from a Danish survey. Dementia and Geriatric Cognitive Disorders Extra, 1, 418-428. doi: 10.1159/000333812.

Kaufer, D.I. et al. (2000). Validation of the NPI-Q, a brief clinical form of the Neuropsychiatric Inventory. The fournal of Neuropsychiatry and Clinical Neurosciences, 12, 233-239. doi: 10.1176/jnp.12.2.233.

Kerpershoek, L. et al. (2019). Optimizing access to and use of formal dementia care: qualitative findings from the European Actifcare study. Health $\mathcal{E}$ Social Care in the Community, 27, e814-e823. doi: 10.1111/hsc.12804.

Kørner, A., Lauritzen, L., Lolk, A., Abelskov, K., Christensen, P. and Nilsson, F.M. (2008). The Neuropsychiatric Inventory-NPI. Validation of the Danish version. Nordic Fournal of Psychiatry, 62, 481-485. doi: 10.1080/08039480801985146.

Levac, D., Colquhoun, H. and O'Brien, K.K. (2010). Scoping studies: advancing the methodology. Implementation Science, 5, 69. doi: 10.1186/1748-5908-569.

Mansfield, E., Boyes, A.W., Bryant, J. and Sanson-Fisher, R. (2017). Quantifying the unmet needs of caregivers of people with dementia: a critical review of the quality of measures. International fournal of Geriatric Psychiatry, 32, 274-287. doi: 10.1002/gps.4642.

Marais, I. and Andrich, D. (2008). Formalizing dimension and response violations of local independence in the unidimensional Rasch model. Fournal of Applied Measurement, 9, 200-215.

Maribo, T., Lauritsen, J., Wæhrens, E.E., Poulsen, I. and Hesselbo, B. (2006). Barthel indeks til vurdering af funktionsevne: Dansk konsensus om brug. Ugeskrift for Lager, 168, 2790-2792.

McCabe, M., You, E. and Tatangelo, G. (2016). Hearing their voice: a systematic review of dementia family caregivers' needs. The Gerontologist, 56, e70-e88. doi: 10 .1093/geront/gnw078.

Ministry of Health and the Elderly (Ed.) (2017). Komitéloven. Bekendtgørelse af lov om videnskabsetisk behandling af sundhedsvidenskabelige forskningsprojekter. LBK nr. 1083. 15 September 2017.

Muthén, L.K. and Muthén, B.O. (1998-2017). Mplus User's Guide. 8th ed. Los Angeles, CA: Muthén \& Muthén.

Neville, C., Beattie, E., Fielding, E. and MacAndrew, M. (2015). Literature review: use of respite by carers of people with dementia. Health $\mathcal{E}$ Social Care in the Community, 23, 51-63. doi: 10.1111/hsc.12095.

Nielsen, T.R., Nielsen, D.S. and Waldemar, G. (2019). Barriers to post-diagnostic care and support in minority ethnic communities: a survey of Danish primary care dementia coordinators. Dementia, 1-12. doi: 10.1177/ 1471301219853945.

Novais, T., Dauphinot, V., Krolak-Salmon, P. and Mouchoux, C. (2017). How to explore the needs of informal caregivers of individuals with cognitive impairment in Alzheimer's disease or related diseases? A systematic review of quantitative and qualitative studies. BMC Geriatrics, 17, 86. doi: 10.1186/s12877-017-0481-9.

Polit, D.F., Beck, C.T. and Owen, S.V. (2007). Is the CVI an acceptable indicator of content validity? Appraisal and recommendations. Research in Nursing $\mathcal{E}$ Health, 30, 459-467. doi: 10.1002/nur.20199.

Prince, M., Guerchet, M.M., Ali, G.C., Wu, Y. and Prina, M. (2015). World Alzheimer Report 2015 - The Global Impact of Dementia: An Analysis of Prevalence, Incidence, Cost and Trends. London: Alzheimer's Disease International.

Queluz, F.N., Kervin, E., Wozney, L., Fancey, P., McGrath, P.J. and Keefe, J. (2019). Understanding the needs of caregivers of persons with dementia: a scoping review. International Psychogeriatrics, 1-18. doi: 10.1017/ S1041610219000243.

Sainsbury, A., Seebass, G., Bansal, A. and Young, J.B. (2005). Reliability of the Barthel Index when used with older people. Age and Ageing, 34, 228-232. doi: 10.1093/ageing/ afi063.

Schreiber, J.B., Nora, A., Stage, F.K., Barlow, E.A. and King, J. (2006). Reporting structural equation modeling and confirmatory factor analysis results: a review. fournal of Educational Research, 99, 323-338. doi: 10.3200/JOER.99 .6.323-338.

Schulz, R. and Sherwood, P.R. (2008). Physical and mental health effects of family caregiving. The American 
Fournal of Nursing, 108, 23-27. doi: 10.1097/01.NAJ $.0000336406 .45248 .4 \mathrm{c}$.

Sharma, T., Bamford, M. and Dodman, D. (2015). Person-centred care: an overview of reviews. Contemporary Nurse, 51, 107-120. doi: 10.1080/10376178.2016 .1150192 .

Stephan, A. et al. (2018). Barriers and facilitators to the access to and use of formal dementia care: findings of a focus group study with people with dementia, informal carers and health and social care professionals in eight European countries. BMC Geriatrics, 18, 131. doi: 10.1186/s12877018-0816-1.

Stirling, C., Andrews, S., Croft, T., Vickers, J., Turner, P. and Robinson, A. (2010). Measuring dementia carers' unmet need for services-an exploratory mixed method study. BMC Health Services Research, 10, 122. doi: 10.1186/ 1472-6963-10-122.

Streiner, D.L., Norman, G.R. and Cairney, J. (2015). Health Measurement Scales: A Practical Guide to Their Development and Use. 5th ed. New York: Oxford University Press.

Tatangelo, G., McCabe, M., Macleod, A. and You, E. (2018). "I just don't focus on my needs." The unmet health needs of partner and offspring caregivers of people with dementia: a qualitative study. International fournal of Nursing Studies, 77, 8-14. doi: 10.1016/j.ijnurstu.2017 .09 .011 .
Terwee, C. et $\boldsymbol{a l}$. (2007). Quality criteria were proposed for measurement properties of health status questionnaires. Fournal of Clinical Epidemiology, 60, 34-42. doi: 10.1016/j .jclinepi.2006.03.012.

van der Velde, G., Beaton, D., Hogg-Johnston, S., Hurwitz, E. and Tennant, A. (2009). Rasch analysis provides new insights into the measurement properties of the neck disability index. Arthritis Care $\mathcal{E}$ Research: Official Fournal of the American College of Rheumatology, 61, 544-551. doi: 10.1002/art.24399.

Wade, D.T. (2015). Rehabilitation - a new approach. Part two: the underlying theories. Clinical Rehabilitation, 29, 1145-1154. doi: 10.1177/0269215515601175.

Wade, D.T. (2016). Rehabilitation - a new approach. Part three: the implications of the theories. Clinical Rehabilitation, 30, 3-10. doi: 10.1177/0269215515601176.

Wade, D.T. and Halligan, P. (2017). The biopsychosocial model of illness: a model whose time has come. Clinical Rehabilitation, 31, 995-1004. doi: 10.1177/ 0269215517709890.

Wancata, J. et al. (2005). The Carers' Needs Assessment for Dementia (CNA-D): development, validity and reliability. International Psychogeriatrics, 17, 393-406. doi: 10.1017/ S1041610205001699.

World Health Organization. (2001). ICF - International Classification of Functioning, Disability and Health. Geneva: World Health Organization. 